
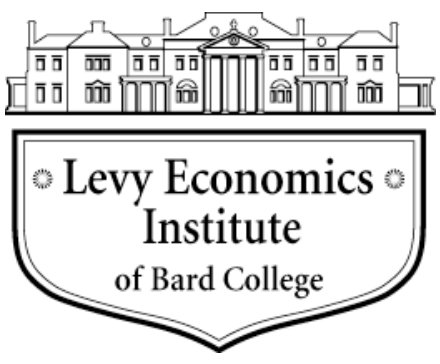

Working Paper No. 799

\title{
Monetary Mechanics: A Financial View
}

by

Éric Tymoigne*

Levy Economics Institute of Bard College

May 2014

* Correspondence: etymoigne@lclark.edu. The author thanks John F. Henry, Charles A.E. Goodhart, Yan Liang, Perry Mehrling, and L. Randall Wray.

The Levy Economics Institute Working Paper Collection presents research in progress by Levy Institute scholars and conference participants. The purpose of the series is to disseminate ideas to and elicit comments from academics and professionals.

Levy Economics Institute of Bard College, founded in 1986, is a nonprofit, nonpartisan, independently funded research organization devoted to public service. Through scholarship and economic research it generates viable, effective public policy responses to important economic problems that profoundly affect the quality of life in the United States and abroad.

Levy Economics Institute

P.O. Box 5000

Annandale-on-Hudson, NY 12504-5000

http://www.levyinstitute.org

Copyright (C) Levy Economics Institute 2014 All rights reserved

ISSN 1547-366X 


\begin{abstract}
This paper develops the framework of analysis of monetary systems put together by authors such as Macleod, Keynes, Innes, and Knapp. This framework does not focus on the functions performed by an object but rather on its financial characteristics. Anything issued by anybody can be a monetary instrument and any type of material can be used to make a monetary instrument, as these are unimportant determinants of what a monetary instrument is. What matters is the existence of specific financial characteristics. These characteristics lead to a stable nominal value (parity) in the proper financial environment. This framework of analysis leads the researcher to study how the fair value of a monetary instrument changes and how that change differs from changes in the value of the unit of account. It also provides a road map to understanding monetary history and why monetary instruments are held.
\end{abstract}

Keywords: Monetary Instrument; Money; Fair Value; Unit of Account JEL Classifications: E5, E42, E44 


\section{INTRODUCTION}

The functional analysis of monetary systems is currently the most popular approach among academics of all disciplines- "money is what money does" (Walker 1878; Hicks 1967; Dalton 1965; Kemp 1956). This approach is used in a narrow way by most economists who focus on the function of the medium of exchange. Further, a unique commodity was progressively sorted out as best for market exchanges (Jevons 1875; Menger 1892) ${ }^{1}$ to avoid the problem of double coincidence of wants. Thus, functionalists argue that a monetary system can be detected by checking for the presence of a medium of exchange, which usually implies searching for objects changing hands frequently. Einzig (1966) and Quiggin (1949) reject this narrow functional approach. Exchange was not done principally, or even at all, for economic reasons, they argue, and so the absence of a double coincidence of wants was not a problem. The broad functional approach classifies anything as a monetary instrument as long as it performs all or parts of the functions attributed to monetary instruments. The distinction between "all-purpose money" and "special-purpose money" follows below (Polanyi 1957).

A main issue with the functional approach is that it does not explicitly define what "money" is. This leads one either to select one main function, or to pick and choose depending on the circumstances. This may lead the one to inappropriately impose their own experience to explain the inner workings of completely different societies (Dalton 1965). In addition, following the functional approach may lead one to the assumption that monetary instruments must take a physical form when they need not ${ }^{2}$ This makes it difficult to convincingly include "money" in models, and, in turn, encourages one to ignore the financial side of the economy. Finally, researchers using this approach may confuse monetary payments and in-kind payments; they may assume that there is a monetary system where there is none, usually leading them to make a truncated analysis of monetary systems consisting in a mere recollection of objects, and may miss the presence of a monetary system (Goldberg 2005).

This paper presents an alternative framework that can be used to analyze monetary systems by drawing on the work of Smith (1811, 1832), MacLeod (1889), Knapp (1904), Innes (1913, 1914), Hawtrey (1919), Keynes (1930), Murad (1939, 1943, 1954), Olivecrona (1957),

\footnotetext{
${ }^{1}$ See Ingham (2000) for problems surrounding this explanation of the emergence of monetary instruments.

${ }^{2}$ Pryor (1977) is an example of the problems that this creates. Through an empirical analysis, he claims to verify Polanyi's theory of money, but does so by excluding bookkeeping entries that are an important in Polanyi's (Polanyi 1957 (1968), 193).
} 
Wray (1998, 2012), and Ingham (2004), among others. The analysis asks what "money" is instead of what "money" does. Monetary instruments are not defined by what they do, or by what a researcher thinks they do, but by specific financial characteristics. By defining explicitly what "money" is, this framework provides some insights into past monetary systems and into monetary mechanisms.

The first part of this paper presents the analytical framework used in the rest of the paper. Concepts of finance are used to categorize different financial instruments and to explain what "payment" means. The second part of the paper applies this framework to define what a monetary instrument is and analyzes historical events. It shows that the establishment of liquid monetary instruments took time, and that quite a few mistakes were made in the process as a result of misunderstanding of the nature of monetary instruments. The third part synthesizes the previous finding by arguing that the functions performed by monetary instruments are not the primary reasons for why they are held. This section also explains why government financial instruments are more widely accepted than others. The fourth part provides a roadmap to study the history of money using the preceding framework. 


\section{FINANCE: A WORLD OF PROMISES}

\section{Promises and Finance}

The world of finance deals with financial instruments. Financial instruments are promises involving future monetary payments (i.e., future delivery of specific amounts of a specific unit of account). Finance establishes a legal framework for recording the creation and fulfillment of promises, and it measures, more or less accurately, the credibility of these promises at any point in time. These promises are formalized through contracts that serve as financial liabilities for issuers and financial assets for bearers. They are legal acknowledgements that the issuer of the contract (the debtor) owes monetary payments to the bearer(s) of the contract (the creditor).

Promises are created at will by the issuer (the challenge is to find a willing bearer) and the issuer does not have to have at hand what he agrees to deliver to be able to make promises. A pizza coupon (i.e., a promise that provides a free pizza when handed back to the pizza maker) can be created even though no pizza has been made. Banks can create checking accounts that promise government currency on demand even though they may not have any in their vault at the moment of issuance. As long as it is possible to deliver at low cost what is promised when required, it makes sense to issue a promise if needed.

All promises have some similarities. First, the issuer agrees to take back his financial instruments whenever they mature; thereby extinguishing his debt to others:

[The] very nature of credit throughout the world [...] [is] the right of the holder of the credit (the creditor) to hand back to the issuer of the debt (the debtor) the latter's acknowledgment or obligation. [...] Every document or instrument, in whatever form or of whatever material, which gives this right of cancelling a debt by returning it to the issuer is a credit document, an acknowledgement of debt, and "instrument of credit" (Innes 1914, 161).

Reflux mechanisms - channels available to bring back a financial instrument to its issuer - are determined at issuance but can be changed over time at the discretion of the issuer or after mutual agreement with the bearer. Second, financial instruments have specific characteristics (e.g., words, colors, signs, illustrations, shapes, electronic signatures) which, among other purposes, such as limiting forgery, allow bearers to identify the issuer. Third, they all have a face value which is the price at which the issuer will take back his financial 
instrument. ${ }^{3}$ Fourth, they are all denominated in a specific unit of account. Fifth, the nominal value at which bearers are willing to hold a financial instrument is based on a discounted value of the future monetary payment(s) promised - the fair value, represented as:

$$
P_{t}=\sum_{n=1}^{N} \frac{E_{t}\left(Y_{n}\right)}{\left(1+d_{t}\right)^{n}}+\frac{E_{t}\left(F V_{N}\right)}{\left(1+d_{t}\right)^{N}}
$$

Where the subscript $t$ indicates the present time, $P_{t}$ is the current fair value, $Y_{n}$ is the nominal income promised at a future time $n, F V_{N}$ is the face value that will prevail at maturity, $E_{t}$ indicates current expectations about income and face value, $d_{t}$ is the current discount rate imposed by bearers, $N$ is the time lapse until maturity ( $n=0$ is the issuance time). There is a wide variety of financial instruments that use this formula. At one extreme, there are modern government monetary instruments that provide no income $(Y=0)$, have a zero term to maturity ( $N=0$, they can be redeemed instantaneously from issuance), and are universally expected to be taken back by the government at their initial face value at any time, $P_{t}=F V_{0}$. At the other extreme are consols that have a given expected income and an infinite term to maturity, $P_{t}=$ $E_{t}(Y) / d_{t}$. Financial instruments can circulate at parity (face value), at a discount (below face value), or at a premium (above face value). If collateral exists, the fair value will be equal to the expected value of the collateral in the event of default.

Beyond these similarities, the characteristics of financial instruments vary, by term to maturity, sources of benefits for the bearer, redemption clause, availability of guarantees in case of default, transferability, credibility, and liquidity. These characteristics can be used to classify financial instruments according to their acceptability.

The term to maturity (i.e., the time lapse after which a financial instrument can be handed back to the issuer following full repayment of principal), promises vary from fulfillment on demand to open-ended fulfillment. Stated alternatively, the fulfillment of that component of a promise depends either on the choice of the bearer (zero term to maturity), or the passing of a specific period of time or occurrence of a contingency over a period of time, or the choice of the issuer (infinite term to maturity).

\footnotetext{
${ }^{3}$ The fact that the face value is the price at which the issuer takes back his promise is evident when that face value is not written down (medieval coins). Today, the initial face value is marked on a promise, but it is implicitly changed if the promise is accepted by its issuer at a different value because the fair value will converge toward that new value.
} 
In terms of sources of benefits for the bearer, a financial instrument may promise timely income payments, payments depending on the occurrence of a contingency, or payments at the request of the issuer. Some financial instruments give a bearer a say in the economic affairs of the issuer. Modern government monetary instruments make no such promise (they pay no income); common stocks provide a dividend depending on the occurrence of a profit and at the discretion of the issuer; insurance contracts pay if a specific event occurs, and all other promises make an income payment at specific dates (e.g., coupons, interest payments).

In terms of the redemption clause, there are two main means for a bearer to redeem a promise. First, a promise contains a conversion clause that states whether or not a bearer has the right to take delivery at maturity of another promise, usually considered more acceptable. For example, bank accounts promise to deliver government currency on demand and government currency may promise to deliver gold coins or a "strong" foreign currency on demand. The conversion clause of many contemporary government monetary instruments states that they are unconvertible. Second, in addition to the conversion clause, there is usually another redemption clause that may allow the bearer to redeem a promise by using it to pay obligations due to the issuer.

In terms of availability of guarantees, promises can be secured or unsecured and specify available recourses, if any. Other forms of guarantees come in terms of the seniority of promises in the bankruptcy process. These guarantees protect the bearer in case the issuer reneges on his promise ( i.e., defaults). In terms of collateral, this protection is provided not by the collateral itself (e.g., house, car, gold, etc.) but by its market value; this market value helps the bearer to get access to the unit of account despite the default of the issuer, and so helps to preserve the bearer's liquidity and solvency. Modern government monetary instruments are unsecured, nonrecourse financial instruments. Previous monetary instruments like gold coins or gold certificates were secured but not necessarily up to face value. Other commodities like land were also a popular form of collateral because a monetary system anchored on a commodity was thought to be more stable.

In terms of credibility, some promises are considered more credible because their issuer is expected to be able to fulfill the terms of the promise more easily. The higher the creditworthiness, the lower $d$ given everything else (i.e., the closer to parity the promise will circulate). The discount rate may actually be negative (i.e., a financial instrument circulates at a premium) because the issuer accepts back his financial instrument at a higher value than the 
stamped face value; because of the scarcity of the financial instrument relative to the number of economic agents who are indebted to the issuer and need to pay the issuer immediately or soon; or (3) because of other reasons related to the high credibility of the issuer that make this financial instrument a core component of the financial system. ${ }^{4} \mathrm{~A}$ high degree of convenience associated with a given means of payment may also cause a financial instrument to circulate at a premium among bearers (Hawtrey 1919, p. 176).

In terms of transferability (or negotiability) of ownership, promises that are easier to transfer do not name a specific bearer (i.e., person or organization to whom the promise must be fulfilled); they are impersonal. Monetary instruments have this characteristic and so do financial instruments that trade on an exchange. Other promises, such as mortgages or U.S. savings bonds, are more difficult or impossible to transfer because they name the bearer. Some negotiable promises are in between these two extremes. They can be used by a bearer to pay a third party by changing the name of the bearer through endorsement or, more crudely, by simply removing the name of the former bearer.

In terms of liquidity, some financial instruments circulate more readily at parity at any time or record less fair-price volatility. As such, $d$ is impacted by the views of bearers regarding the ease of quickly disposing of a financial instrument at low cost. Liquidity depends in part on the factors outlined above. For example, a promise that is highly credible, with a short term to maturity, and is negotiable, will be more liquid. Liquidity also depends on the structure of the market in which a financial instrument circulates. For example, the deeper the market and the more transparent the information, the more liquid a financial instrument will be, because expectations influencing the fair value will be more stable. As such, liquidity is not intrinsic to any financial instrument. It is the result of its characteristics and a well-functioning financial infrastructure.

Finally, within a country, there is a hierarchy of financial instruments in the sense that some are more accepted by bearers. The most generally accepted financial instruments are those that are negotiable, of the highest creditworthiness, of the highest liquidity, and of the shortest term to maturity. In contemporaneous economies with a monetarily sovereign government, central bank monetary instruments are at the top of the hierarchy. They are followed by bank monetary instruments that were made perfectly liquid following the emergence of interbank par-

\footnotetext{
${ }^{4}$ This explains why nominal interest rates on US treasuries can be negative (Cecchetti 1988, Clouse et al. 2000; Fleming and Garbade 2004).
} 
clearing and settlement and deposit guarantees. ${ }^{5}$ Below monetary instruments are financial instruments traded on an exchange (issued mostly by governments and corporations). At the bottom of the hierarchy, there are all sorts of promises, such as local currencies and personal debt. This hierarchy is not fixed, and throughout history, the top monetary instrument has not always been government currency.

\section{Fulfillment of Promises: Means of Settlement}

To "pay" means to fulfill the promises embedded in a financial instrument, that is, to deliver the promised amount of monetary units (Innes 1913; Mann 1992, p. 64). ${ }^{6}$ As such, payment involves transferring a certain amount of a unit of account from the debtor to the creditor. However, contrary to non-financial promises (e.g., a pizza coupon), financial promises do not specify what form the delivery of these units should take. Outside of courts, payment can take any form as long as the creditor agrees.

A payment is not final (i.e. it does not release a debtor from potential legal action by their creditors) if the debtor makes a payment through endorsement and other similar methods that involve guaranteeing a third-party promise used to pay creditors. Only payments with a legal tender are final in court disputes. Legal tender used may not be a monetary instrument and does not define it as a monetary instrument. For example, Maryland made tobacco a legal tender at a penny per pound of tobacco in 1732 (Markham 2002, 46) even though tobacco was not a monetary instrument (see last section). ${ }^{7}$ Payment in tobacco (like the payments of some taxes in medieval times) was a payment in kind. Outside of the courts, one way a payment is considered to be final is when an issuer receives their own promises as means of payment from their debtors.

Simply stating "I owe you ten dollars" does not mean that someone promises to deliver cash or any other specific form of monetary instruments for a total of ten dollars. It also does not mean that someone promises to provide in the future the equivalent of what is currently $\$ 10$

\footnotetext{
${ }^{5}$ Prior to the existence of a central bank and deposit guarantee, the subordination of all other bank promises to banknotes (i.e., banknote bearers would be compensated first if the bank went bankrupt) helped banknotes to circulate closer to parity (Nussbaum 1957, 69).

6 "To pay" comes from the Latin word pacare, "to please, pacify, satisfy," especially "to satisfy creditors" in medieval Latin.

${ }^{7}$ Legal scholars such as Nussbaum (1950, p. 54) and Kemp (1956, p. 45) provide many examples of commodities used as a legal tender even though the latter argues that legal tender laws (finality of payment) define "moneyness" while the former does not. Hirschberg (1971, p. 43) sides with Nussbaum and Kemp sides with Mann (1992, pp. 5$6)$.
} 
worth of purchasing power. ${ }^{8}$ It only means that someone promises to deliver ten units of the unit of account named "Dollar." These ten dollars can be delivered in many forms. One way is to give back to a bearer some of their promises for an amount equal to $\$ 10$; this is a case of net clearing. Another way, if a debtor does not own his creditor's promises (or if they have not matured yet), involves transferring a unit of account by using a third-party promise. Usually, this is done with a promise of a greater acceptability; however, settlement could be done with a hierarchically lower form of promise than the promise that it clears. Finally, payment in-kind or with a financial instrument denominated in another unit of account can also be a solution for settling a promise as long as the payments are worth $\$ 10$ (in a bankruptcy process, creditors may have to settle for less).

For example, let us assume that ten units of Dollar were created through the issuance of a promise by a firm $\mathrm{F}$ to a bank $\mathrm{B}$ (promissory note) in exchange for the promise of the bank (bank account) (Figure 1):

Figure 1 Bank Advance: An Exchange of Promises

Bank B

\begin{tabular}{c|l}
\hline \multicolumn{1}{c|}{$\Delta$ Assets } & \multicolumn{1}{|l}{ Liabilities } \\
\hline Promissory & Bank \\
note of $\mathrm{F}$ & account of \\
$+\$ 10$ & $\mathrm{~F}+\$ 10$
\end{tabular}

Firm F

\begin{tabular}{l|l}
\hline \multicolumn{1}{c|}{$\Delta$ Assets } & \multicolumn{2}{|c}{$\Delta$ Liabilities } \\
\hline Bank & Promissory \\
account at & note to B \\
$\mathrm{B}+\$ 10$ & $+\$ 10$
\end{tabular}

Then $\mathrm{F}$ uses the funds in its bank account for any purpose it chooses. At maturity, F must take back its promissory note by giving $\$ 10$ to bank $\mathrm{B}$. This can take many forms. First, firm $\mathrm{F}$ will usually make a profit so its bank account at B will be credited by more than $\$ 10$. F can then give back to B \$10 worth of B's promises (B's banknotes or debiting of \$10 from F's bank account at B). In exchange, B gives back to $\mathrm{F}$ (or destroys) its promissory note. This net clearing leads to the exact opposite balance sheet transaction relative to Figure 1. Another solution is for $\mathrm{F}$ to give to $\mathrm{B}$ some government monetary instruments. The bank may also accept in payment

\footnotetext{
${ }^{8}$ Legal scholars discuss this issue in terms of Nominalism versus Valorism (Hirschberg 1971). Given that Nominalism prevails today in the law, the prevailing view among economists that a monetary instrument is a claim on goods and services is incorrect. A monetary instrument only carries a stable nominal amount of a unit of account; it does not promise that this nominal amount has stable purchasing power, but it can extinguish a stable amount of debt.
} 
from $\mathrm{F}$ a promissory note from another firm, F1 (Figure 2). In this case, the payment is not final because if $\mathrm{F} 1$ defaults on its promise, $\mathrm{F}$ must pay $\mathrm{B} .{ }^{9}$ A payment will usually be final only if $\mathrm{F}$ delivers the promised monetary units via the use of B's, or higher level, financial instruments, which do not have to be a legal tender. ${ }^{10}$ As long as the bank agrees, a payment in kind would also be final and would replace the entry "promissory note of F1" with a physical object.

Figure 2 Settlement of Promise of firm F (no discount)

Bank B

\begin{tabular}{l|l}
\hline$\Delta$ Assets & $\Delta$ Liabilities \\
\hline Promissory note & \\
of F $-\$ 10$ & \\
Promissory note & \\
of $F 1+\$ 10$ &
\end{tabular}

Firm F

\begin{tabular}{l|l}
\hline$\Delta$ Assets & $\Delta$ Liabilities \\
\hline Promissory & Promissory \\
note of F1 $-\$ 10$ & note at B $-\$ 10$
\end{tabular}

\footnotetext{
${ }^{9}$ Payments in that form used to be a crucial means of business operations and are at the origins of the emergence of merchant bankers who were dealers in bills of exchange (Boyer-Xambeu et al. 1994; Hawtrey 1919).

${ }^{10}$ Similarly, economic agents indebted to firm $\mathrm{F}$ can make a payment to $\mathrm{F}$ that is considered final by handing to $\mathrm{F}$ some maturing promissory notes that $\mathrm{F}$ issued in the past.
} 


\section{MONEY AND THE WORLD OF PROMISES}

\section{What is Money?}

The preceding section provides an alternative way to define "money" based on what it is rather than what it does. A monetary system is composed of two elements: a unit of account and monetary instruments. Contemporaneous government monetary instruments are just a specific sort of promise. They are unconvertible, zero-coupon, zero-term-to-maturity, negotiable, unsecured, non-recourse financial instruments denominated in a unit of account. Bank monetary instruments are similar except that there is a recourse (they are not legal tenders) and they are convertible. Gold coins are similar to modern government instruments except that they are secured; however, the gold content is not the monetary instrument - the coin is.

To work properly as a monetary instrument, financial instruments must have a very short term to maturity (zero term to maturity is best), something that was not always understood throughout history:

Paper money has no intrinsic value; it is only an imputed one; and therefore, when issued, it is with a redeeming clause, that it shall be taken back, or otherwise withdrawn, at a future period. Unfortunately, most of the governments, that have issued paper money, have chosen to forget the redeeming clause, or else circumstances have intervened to prevent their putting it into execution; and the paper has been left in the hands of the public, without any possibility of its being withdrawn from circulation (Smith 1832, p. 49)

Probably, no government paper money was ever sent forth which was not expected to be redeemed in full value, at some time, although that might be distant. [...] Nevertheless, the issues of government money that have not been redeemed, or the payment of which has been either formally or tacitly renounced, have been very numerous. (Langworthy Taylor 1913, p. 309)

By not creating any means for their monetary instruments to reflux, some governments had effectively imposed an infinite term to maturity so the fair value was zero. ${ }^{11}$ The importance of this reflux for the stability of a monetary system was already recognized, albeit imprecisely, by John Law in 1705 (Vickers 1959, 133-134).

\footnotetext{
${ }^{11}$ As explained below, some monetary instruments may have non-monetary uses, so their numismatic value may be much higher than their fair value. For example, a $\$ 1$ silver certificate can be used to pay the US Treasury. However, the US Treasury will only accept it in payments at face value while some $\$ 1$ certificates can be sold to collectors for tens of thousands of dollars. The fair value as a monetary instrument is $\$ 1$, but the numismatic value may be much higher (or lower).
} 
The nature of the conversion clause in a financial instrument does not define what a monetary instrument is. In the literature, this conversion clause is used to show the difference between "money" and "credit," with "credit" (e.g., bank accounts or banknotes) being a claim on "money" (e.g., gold coins). This distinction is not relevant because even full-bodied gold coins are financial instruments (i.e. promises); they are unconvertible financial instruments that issuers promise to accept at any time in payments due to them. As such, over time their fair value may differ from the market value of the gold content. The word "credit" comes from the Latin word for trust and all monetary instruments, being promises, require trust in the financial abilities of the issuer. ${ }^{12}$ Thus, the nominal value of a financial instrument is inherently forwardlooking. It is not based on its cost of production - a backward-looking method of valuation used partly to sell commodities - but rather on the credibility of the issuer.

The unit of account is not a function of money; it is one of the characteristics of a monetary system; the other one is the existence of monetary instruments. A unit of account is an abstract, nominal, and arbitrary ${ }^{13}$ scale of measurement for accounting purposes. Its purpose is strictly to make economic transactions commensurable. As such, the unit of account cannot be a medium of exchange, a store of value, or a means of payment. Stated another way, a monetary system requires a unit of account and carriers of this unit of account, but they have separate roles - one measures, and the other records the measurement.

A unit of account can take the name of an object; however, once created, it has an independent existence from the object. This manifests itself in two ways. The object may disappear, but the unit of account used for the monetary system persists, or the relationship between the unit of account and the object can change. For example, a cowry unit of account

\footnotetext{
${ }^{12}$ The argument is not related to the societal/conventional theory of money: "I accept money because others do." The argument is about the trust of bearers relative to the capacity of the issuer to fulfill his promise, instead of being about the trust of bearers relative to the willingness of other bearers to accept a promise. While societal trust (trust of bearers about other bearers) may help financial instruments to circulate more broadly, the trust at the core of the circulation of a financial instrument is the financial credibility of the issuer (trust of bearers about the issuers' willingness and ability to pay). Without the latter, the fair value of an unsecured non-recourse unconvertible financial instrument falls to zero.

${ }^{13}$ The name of some units of account originated in the weight units, but rapidly lost their connection to them (e.g., a pound sterling is not represented by a pound of fine silver, a pound sterling is just a pound sterling) (Smith 1832, p. 20; Murad 1939; Olivecrona 1957). Other names of units of account are just made up, sometimes to reflect political or cultural aspirations (the "Euro"), and have never had anything to objectify them. In some ways, units of account are similar to family names; they just allow us to know to which family one belongs. Some family names originate from physical conditions (Short, Blind, etc.) or professions (Archer, Baker, etc.) but people carrying factual surnames do not have to have that physical condition or perform that profession. The analogy also helps to understand why a unit of account cannot be a medium of exchange or a means of payment. The surname "Archer" does not eat, work, or breathe, but a person who carries that surname does.
} 
may exist without any cowry shell being used in transactions. If cowries are used, their value in terms of the cowry unit may change-one cowry shell may be worth one cowry at one time and three cowries at another time. Similarly, a coin with a denomination of one French franc issued before 1960 was worth one French franc, but only one centime of a French franc after. This change in the method of recording accounts is completely at the discretion of the monetary authority. This change does not represent a change in the value of the unit of account within the domestic economy because the value of everything in the country is redefined to correspond to the new counting method. It, however, does represent a change in the relative value of units of account (devaluation or reevaluation).

There cannot be monetary instruments without a unit of account but there can be a unit of account without monetary instruments. By historical accounts, units of account created by religious authorities emerged around 3000 B.C. in Mesopotamia and later in Egypt in order to improve the administration of their planned economies. It was the end result of a long quest to develop a numerical system, starting from 8000 B.C. with concrete counting to 3100 B.C., with the creation of abstract counting (Schmandt-Besserat 1992; Nissen, Damerow, and Englund 1993). While a unit of account was present, there was no financial instrument issued to bearers - all accounting records were for internal purposes of the temple, and all dues to the authorities by the population were paid in-kind (Hudson and Wunsch 2004; Henry 2004). Financial instruments appeared around 1800 B.C. and negotiability progressively emerged around that time, too, long before coins (Van De Mieroop 2005).

Given that a monetary instrument is a promise, one may wonder what kind of promise the issuer of a monetary instrument makes (what does the issuer owe the bearer?). In the case of modern unconvertible currency, the only promise that the government makes is to accept its monetary instruments at any time for payments of debts due to the government (with some exceptions for safety, tractability of payment, and others in which case government monetary instruments are returned to the government through the private banking system). Private banks make two promises when they issue monetary instruments: one is to accept them at any time as means of payment from debtors; the other is to convert them into government monetary instruments at any time. 


\section{Fair Value of a Monetary Instrument}

Promises in the form of financial instruments have a face value, but they may not circulate among bearers at face value. This section explains why this may be the case for monetary instruments. To clarify, this section is not concerned with explaining inflation (i.e., changes in the value of the unit of account relative to goods and services) or exchange rate (i.e., changes in the value of the unit of account relative to another unit of account). This section is concerned with the nominal circulation value of a promise (i.e., why it circulates at parity, at a discount, or at a premium). For example, a one-dollar banknote may circulate at a nominal value of fifty cents or two dollars and this is what this section explained. This section does not explain why a one-dollar note circulating at one dollar may buy more or less goods and services over time, which is the subject of the next section. While both effects lead to the same result (i.e., changes in purchasing power), the mechanisms at play are different.

Given the characteristics of monetary instruments, they should circulate at parity all the time; however, circulation at par does not define a monetary instrument. Par circulation is only the result of the inner characteristics of a financial instrument together with the existence of proper financial infrastructure that allows these characteristics to be expressed in the fair value. For reasons related to poor technics of production, inexperience, political instability, fraud, and poorly developed banking system, it took quite a long time for this infrastructure to be established. This section takes three examples that illustrate that point: the bills of credit of the Massachusetts Bay colonies, the banknotes issued during the Wildcat Era in the United States, and the precious metal coins issued during the Middle Ages.

The Massachusetts Bay colonies responded to a lack of currency by issuing bills of credit that "shall be accordingly accepted by the treasurer and receivers subordinate to him, in all public payments, and for any stock at any time in the treasury" (Davis 1900, 10). Technically, they had a zero term to maturity (accepted in payments at any time), but the tax imposed to retire the bills was levied at a later date. Thus, bearers had limited opportunities to test the credibility of the promise at issuance, so the term to maturity was not effectively zero. This created uncertainty for bearers because they were unsure that the government would enforce the tax (a concern that turned out to be justified as explained in the next section). Thus, when bills were issued for the first time, $d$ was positive for economic and political reasons, and the bearers' expectations about the term to maturity $(E(N))$ compounded the discount applied to the bills. 


$$
P_{t}=\frac{F V}{\left(1+d_{t}\right)^{E(N)}}
$$

Initially, the government asked for help from Boston merchants (who agreed to take the bills as payments at a small discount) and the government tried to offset the discount by accepting its bills at a five-percent premium relative to the printed face value (in the formula above $F V$ would rise). The five-percent premium rapidly became unnecessary ${ }^{14}$ as bearers found that tax collection was prompt, and so $d$ declined to zero:

When the government first offered these bills to creditors in place of coin, they were received with distrust. [...] their circulating value was at first impaired from twenty to thirty per cent. [...] Many people being afraid that the government would in half a year be so overturned as to convert their bills of credit altogether into waste paper, [...]. When, however, the complete recognition of the bills was effected by the new government and it was realized that no effort was being made to circulate more of them than was required to meet the immediate necessities of the situation, and further, that no attempt was made to postpone the period when they should be called in, they were accepted with confidence by the entire community [...] [and] they continued to circulate at par (Davis 1900, 10, 15, 18, 20).

However, as explained below, tying the issuance of bills of credit to a specific tax created problems. Over time, these problems contributed to the return of a positive discount as well as a decline in the value of the unit of account.

Prior to the existence of a central bank that provides a uniform monetary system through clearing and settlement at par of bank monetary instruments, banknotes usually circulated at a discount. In the U.S., private initiatives like the Suffolk Bank established an interbank parclearing system that did allow par-circulation of banknotes in New England. Only the Second Bank of the United States had banknotes that circulated at par on the whole national territorydue to the fact that its banknotes were acceptable as payments due to the US government (Markham 2002, 134).

Given that most banks had a limited geographic area of business dealings and the lack of interbank par-clearing and settlement, it was not always possible for all bearers of banknotes to give them back to the issuing bank on demand (either directly or through another bank). As such, the term to maturity of the banknotes was not effectively instantaneous, while the

\footnotetext{
${ }^{14}$ While unnecessary, the acceptance of bills at a five-percent premium proved difficult to move away from. It became a custom and did not disappear until 1720 (Davis 1900, p. 17).
} 
confidence in the capacity of the issuing bank to be a profitable business was not necessarily high. If the issuing bank closed, the banknotes it issued became worthless given that none of the bearers could use them to make payments to that bank. A discount that varied with the confidence about the viability of a specific bank was applied. In addition, due to a lack of regulation during the Wildcat Era, fraud was common. Banks discouraged or refused conversion in specie on demand:

Banks sometimes used remote locations as their redemption points in order to avoid having to redeem their notes in specie. Another method used by the banks to discourage specie demands was to refuse to accept their own notes, except at a large discount. Customers were told that, if they waited, the notes would be later redeemed at par, but such promises were not always kept. The states attempted to require the banks to re-deem at par, but those efforts did not meet with success. (Markham 2002, p. 169)

The violation of the conversion clause further increased the discount applied to banknotes. ${ }^{15}$ This problem was compounded by widespread forgeries (Smith 1832, p. 66) that reinforced the reluctance of banks to take their notes immediately at par, even in payments from debtors, because the validity of the note could not be established.

Finally, the most complex historical case regarding the fair value of monetary instruments concerns medieval coins made of precious metal. There are three broad problems in this case. One relates to the face value of the coins, another relates to the intrinsic value of the coins (i.e., the market value of the precious metal content), and a third problem relates to the interaction between the first two problems.

Until very recently, the face value was not stamped on the coin so it "was carried out by royal proclamation in all the public squares, fairs, and markets, at the instigation of the ordinary provincial judges: bailiffs, seneschals, and lieutenants" (Boyer-Xambeu et al. 1994, p. 47). This announcement declared at what value the king would take each of his coins in payments due to him; thereby establishing their face value. With kings and other individuals issuing coins in an unregulated system, it was hard to know the official face value of a coin. Kings and other issuers confused the public about the current face value by crying coins down or up too often (i.e., changing their face value). Crying down the coinage was an often-used method of increasing

\footnotetext{
15 Nussbaum (1957, p. 65) wonders why banknotes were still accepted in third-party transactions when the conversion clause was violated. The reason is that banks still accepted their banknotes from their debtors; people could repay their debts to a bank by handing back its banknotes (Ibid. p. 64).
} 
taxes (and also a form of default). If one had previously delivered one coin to pay taxes, now one had to deliver two if the sovereign lowered the nominal value of coins by half. Frequent changes in face value led to situations in which "there were so many edicts in force referring to changes in the [face] value of the coins, that none but an expert could tell what the [face] value of various coins of different issues were, and they became highly speculative commodities" (Innes 1913, p. 386).

Coins made of precious metals were a way to deal with some of the uncertainty surrounding the face value of coins. Coins with high precious metal content would be demanded from sovereigns who could not be trusted, either because they cried down their coins too much, refused some of their own coins in payments too often, or were weak politically. The higher the content of precious metal relative to the face value, the more limited the capacity of kings to cry down the coinage because coins would disappear if the face value fell below the market value of the precious metal content (Hawtrey 1919, 173). Coins would be melted (or exported as bullion) to extract the precious metal because a greater number of the unit of account could be obtained per coin by selling the precious metal content instead of handing over coins to the king. Finally, others demanded payments in precious metal coins because they did not expect to be debtor to the king (e.g., mercenaries).

The issuance of such coins created several issues related to their intrinsic value and its impact on the fair value. If circumstances in the precious metal market pushed the value of the precious metal higher than the prevailing face value, mint masters and money changers would melt or illegally debase (via clipping and sweating) the coinage even if the creditworthiness of a king was excellent (Boyer-Xambeu et al. 1994, p. 45). In theory, illegal debasements would occur until the intrinsic value was brought back to the face value, but it became such a habit that it continued even when the value differential was nil (Murad 1939, pp. 27-29). Expectations about future increases in the price of the precious metal (or future crying down) also encouraged illegal debasement even if no profit could be made immediately. Fraud was further encouraged by imperfect production methods. Coins with the same denomination and date of issuance had different weight and fineness even under the best circumstances (Mélitz 1974, p. 71). Coins also had uneven edges that made clipping difficult to notice if done moderately.

Fraud was problematic because it disturbed the uniformity and order that kings wanted to establish to create confidence in their coinage; the stamp on full-bodied coins partly being a certificate of authenticity of the weight and fineness of the collateral embedded in coins 
(Macleod 1894). The king's reputation was at stake. If allowed to continue, the country was left with a coinage of insufficient quantity and quality to promote smooth economic operations, and clumsy and deformed coinage encouraged forgery. In order to prevent this from happening, kings actively fought any fraudulent alteration of the intrinsic value of coins. They did so through several means. One was to punish severely fraudsters:

The coins were rude and clumsy and forgery was easy, and the laws show how common it was in spite of penalties of death, or the loss of the right hand. Every local borough could have its local mint and the moneyers were often guilty of issuing coins of debased metal or short weight to make an extra profit. [...] [Henry I] decided that something must be done and he ordered a round-up of all the moneyers in 1125. A chronicle records that almost all were found guilty of fraud and had their right hands struck off (Quigguin 1963, pp. 57-58).

Another means was to weigh the coins that were brought to pay dues, and to refuse to accept payment in any coins that had a lower weight than at issuance. Finally, two other ways were to debase or to cry up the coinage:

debasements were only necessary alterations in the quantity of silver in the coins, in order to keep pace with the rise in the price of silver bullion in the market; [...] It has always been necessary to regulate the quantity of metal in the coins, because, if too much was put in, they would immediately be withdrawn from circulation and sold for bullion, [...]; if too little was put, they might be imitated (Smith 1832, p. 34).

In this case, debasement was not a means to increase the financing capacity of the king. It was a legitimate means to preserve the stability of a monetary system in which the value of precious metal played a role as collateral (Hawtrey 1919, pp. 280-281). The rising price of precious metals was the cause of debasement, not the other way around. And the rising price of precious metal had to be found partly in their short supply relative to the demand by kings to fund their wars and other lavish expenses, and more broadly in persistent trade deficits that drained coins out of the country.

Debasement was a limited solution to offset the rising price of precious metals because the risk of forgery grew with further debasement. Debasement also negatively impacted the king's creditworthiness even though, in this case, he may have had nothing to do with the problem and was trying to promote a stable monetary system. Crying up the coins was not 
constrained by the risk of forgery, but it created another problem as potential inflationary pressures emerged when the nominal value of the money supply was raised unilaterally overnight. Price pressures in the precious metal market could creep into the market for goods and services, and, once again, the king would be blamed. Finally, frequent crying up created more public confusion about the face value of coins, and reinforced distrust and the demand for coins with a high content of precious metal.

If one combines the first point (changes in face value) and second point (changes in intrinsic value), as well as their interactions, the determination of the fair value of coins becomes complicated. On one side, abusing crying down led to two types of speculation, one regarding the occurrence of a future crying down, another concerning the face value of the coins relative to the value of the precious metal content. On the other side, developments in the precious metal markets affected expectations about future debasements or crying up of coins. Thus, the fair value of coins could fluctuate greatly within a band determined, at a minimum, by the discounted expected cried-down face value at a time $m$ or the current market value of the content of precious metal $\left(P_{G t} Q_{G t}\right)$, and, at a maximum, by the discounted expect resale value of a given quantity of precious metal in the coin at a time $n$ or the discounted cried-up face value at time $q$.

$$
P_{t} \in\left[\max \left(P_{G t} Q_{G t}, \frac{E_{t}\left(F V_{m}^{\text {min }}\right)}{\left(1+d_{t}\right)^{m}}\right), \max \left(\frac{\left.E_{t}\left(P_{G n}\right) Q_{G t}\right)}{\left(1+d_{t}\right)^{n}}, \frac{E_{t}\left(F V_{q}^{\max }\right)}{\left(1+d_{t}\right)^{q}}\right)\right]
$$

Expectations about legal and illegal debasements $\left(E\left(Q_{G}\right)\right)$ would add another layer of complexity, even more so if the time horizon of expectations regarding debasements differed from that regarding the price of precious metal. Thus, coins may have circulated at a premium (only for a short time if crying up was not expected ${ }^{16}$ ), or at a discount, relative to their official face value for complex reasons related to the changes in expectations regarding the future fair value of coins, divergence of these expectations among the population, confidence in these expectations, and the time horizons of these expectations. These expectations were in turn dependent on the credibility of the king (and so socio-politico-economic forces at play in ever changing territories of influence), the existence of fraud, and speculation in the gold and silver markets and its impact on the face value and intrinsic value of coins.

\footnotetext{
${ }^{16}$ Unless one of the special conditions presented in the first section for circulation at a premium prevailed.
} 
Finally, another problem during the Middle Ages was the difficulty of communicating information about changes in the face value efficiently due to an underdeveloped banking system. This led to long delays in the adjustment of the fair value to a new face value. Given the frequency of changes, the fair value may never have had a chance to adapt fully. In addition, some bearers of the king's coins may have been in isolated areas where the king's officials, or merchants, rarely went. This led some coins to circulate at a discount between third parties because it was impossible to return coins to the king at will (either directly or through the banking system). Given the difficulties in ascertaining the fair value of coins and the presence of widespread fraud, it is not surprising that coins would be weighed and would circulate at their bullion value. This is all the more common once a king made the weighing of coins a precondition for their acceptance in payments due to him; weighing became common in private transactions (Wray 2012). While not demonetized unless refused by the king or illegally melted down by bearers, coins would effectively be treated as a commodity by their bearers. In brief, monetary disorder prevailed. The next section argues that this disorder was compounded by the existence of free coinage.

\section{Value of the Unit of Account}

There are situations in which the value of all financial instruments changes at the same time relative to the value of goods and services (inflation or deflation) or relative to another unit of account (depreciation or appreciation). These changes in purchasing power are due either to the discretionary decisions of a monetary authority (e.g., devaluation) or to mechanisms at work in a monetary system. The changes in the value of the unit of account should be differentiated from the changes in the fair value of a monetary instrument (i.e. changes in the real value and nominal value of the monetary instrument should be differentiated). Changes in the value of the unit of account relate to expected and actual changes in macroeconomic conditions. Changes in the fair value relate to expected and actual changes in the characteristics of a financial instrument or in the financial infrastructure. For monetary instruments, this second type of changes has not occurred since government guarantees have been put in place, and unconvertible currency has become common and its supply elastic. These two types of change can produce damaging results in combination as the Massachusetts Bay case shows. 
The value of a unit of account depends on how hard it is to access (Minsky 1986a, chapter 7). To access it one must obtain financial instruments that carry this unit, either by earning an income, by being granted an advance from the suppliers of monetary instruments, or by government spending in the economy. If it is too hard to access the unit of account (e.g., wages are too low, credit standards are too strict, government deficits are too low), the economy will tend to be deflationary. If it is too easy to access, the economy will tend to be inflationary. Leaving aside cost-push inflation, the final effect of inflationary pressures will depend on the elasticity of the supply conditions of goods and services, the way monetary instruments are used, and the strength of the reflux mechanisms.

The same factors affect the relationship between units of account. Reflux mechanisms, like the capacity to export and to receive net income payments from the rest of the world, affect the relative value of the two units of account (Minsky 1986b). In addition, the capacity to accommodate a willingness of economic units in surplus to switch their portfolio into another currency plays a central role. However, because monetary authorities cannot manage the top monetary instruments of other monetary systems, or because they are usually not large enough creditors in foreign currencies, portfolio movements can lead to large depreciations or appreciations of the domestic unit of account relative to foreign units of account unless monetary authorities in different countries coordinate their efforts.

Historical cases help to illustrate some of these points. Starting with the Massachusetts Bay colonies, the provincial government noted the importance of a tax system for the stability of its monetary system; but it also noted that taxes tended to drain too many bills out of the economy compared to what was desired by private economic units. This created a dilemma:

The retirement of a large proportion of the circulating medium through annual taxation, regularly produced a stringency from which the legislature sought relief through postponement of the retirements. If the bills were not called in according to the terms of the acts of issue, public faith in them would lessen, if called in there would be a disturbance of the currency. On these points there was a permanent disagreement between the governor and the representatives. (Davis 1900, 21)

The form of the public bill has already been indicated. It was in effect a certificate of indebtedness, and on that theory, when it found its way back to the treasury the debt was extinguished, and the temporary function of the bill was performed. Under this theory the amounts originally issued each year were simply intended to meet the immediate needs of the government, and 
provision was made for their retirement in the next tax bill. [...] Confidence in the bills was based upon their ultimate withdrawal, and the greater the emissions the greater the taxes that must be levied to provide for their retirement. While this was evidently true, and while there were indications that pointed to a loss of confidence in the bills when the assembly failed to provide the promised fund for the withdrawal of an emission, yet it cannot be doubted, however paradoxical it may seem, that whenever a fund was called in for the purpose of redeeming the government promises and maintaining confidence in the bills, it was expected that there would be an emission to fill the gap thus occasioned in the circulating medium. (Ibid. 380)

Private economic agents desired to hold bills for other purposes than the payment of tax liabilities (e.g., daily expenses, private debt settlements, portfolio choices, and precautionary savings). However, by draining most of the bills via taxes, the government prevented the domestic private sector from accumulating the amount of bills it desired. ${ }^{17}$ At the same time, taxes were a foundational element of the monetary system so they needed to be implemented as expected. Ultimately, the provincial government was unsure about how to proceed in terms of the amount of bills to recall. One drastic method was to breach the promised term to maturity by postponing the implementation of the tax levy for several years. This was an effective default relative to the terms of the bills and a sure means to decrease the confidence in the bills and thus their fair value (ibid., 108); "this fact alone would have caused them to depreciate, even if the amount then in circulation had been properly proportioned to the needs of the community" (Ibid., 20). Later on, the provincial government found a more appropriate solution by broadening the types of obligations that could be paid with the bills.

Some knowledge of national accounting helps to solve this dilemma. The flow of funds accounts use balance sheets to analyze the three main economic sectors of an economy: the domestic private sector $(D P)$, the government sector $(G)$, and the rest of the world/foreign sector (Ritter 1963). To simplify, the foreign sector will be left aside. A balance sheet is an accounting document that records what an economic unit owns (assets) and owes (liabilities and net worth) (Figure 3).

\footnotetext{
${ }^{17}$ The injection mechanisms of Massachusetts bills were also inadequate because they were driven mostly by military needs instead of the needs of the economy (automatic stabilizers and economic development) (Davis 1900, 105ff.). This did not become a severe problem until 1744 when the third French and Indian war started and ultimately destroyed the Massachusetts's monetary system based on unconvertible bills of credit. Until that time, inflation in Massachusetts was contained - 5 to 6 percent annual rate - even if already higher than other colonies (Smith 1985; Brock 1992).
} 
Figure 3 A Basic Balance Sheet

\begin{tabular}{l|l}
\hline Assets & Liabilities and Net Worth \\
\hline Financial Assets $(F A)$ & Financial Liabilities $(F L)$ \\
Real Assets $(R A)$ & Net Worth $(N W)$ \\
\hline
\end{tabular}

A balance sheet must sum to zero, that is, the following equality holds all the time: $F A+R A \equiv$ $F L+N W$. Each macroeconomic sector has a balance sheet (Figure 4).

Figure 4 Balance Sheet of the Domestic Private (DP) and Government (G) Macroeconomic Sectors

\begin{tabular}{l|l}
\hline$A_{D P}$ & $L_{D P}$ \\
\hline$F A_{D P}$ & $F L_{D P}$ \\
$R A_{D P}$ & $N W_{D P}$ \\
\hline
\end{tabular}

\begin{tabular}{l|l}
\hline$A_{G}$ & $L_{G}$ \\
\hline$F A_{G}$ & $F L_{G}$ \\
$R A_{G}$ & $N W_{G}$ \\
\hline
\end{tabular}

Financial assets are claims on other economic sectors. Financial liabilities are claims of other economic units on an economic sector. For every lender there is a borrower, so if one adds together the claims of the lender and the borrower they must cancel out:

$\left(F A_{D P}-F L_{D P}\right)+\left(F A_{G}-F L_{G}\right) \equiv 0$

Given that the previous identity holds in terms of levels, it also holds in terms of changes in levels:

$\Delta\left(F A_{D P}-F L_{D P}\right)+\Delta\left(F A_{G}-F L_{G}\right) \equiv 0$

$\Delta(F A-F L)$ is called net lending or net financial accumulation. If an economic sector accumulates more claims on the other sectors than the other sectors accumulate claims on the sector in question, the economic sector is a net lender: $\Delta(F A-F L)>0$. It is quite straightforward to notice that not all sectors can be net lenders at the same time. For every lender there must be a borrower. 
Usually the domestic private sector desires to have a net financial accumulation of government financial instruments so the government sector must be in deficit. ${ }^{18}$ However, by linking the issuance of its bills of credit to a specific tax, the Massachusetts colonial government took on two impossible tasks to accomplish simultaneously: fulfilling the term to maturity of bills and providing an adequate supply of monetary instruments. There should be a term to maturity and it should be implemented as expected by bearers, but, for monetary instruments, the redemption should not be tied to a specific reflux mechanism and should be left to the discretion of the bearers. By doing this, the issuer avoids creating specific expectations from bearers beyond the knowledge that term to maturity is zero and that payments to the issuer are due and can be made by using the issuer's monetary instruments. This also contributes to an elastic supply of monetary instruments by allowing to remove quickly from the economy any unwanted quantity of monetary instruments. The injection and removal of monetary instruments must be demand-driven to have a smoothly operating monetary system.

While the Massachusetts experiment provides an example of inadequate reflux mechanisms, free coinage provides an example of inadequate injection mechanisms. Anybody who had gold or silver could issue the king's monetary instruments by going to the local mint (Helfferich 1927, p. 370). The metal was accepted without question and coins were struck with the distinctive sign and shape that the king used. The king accepted in payments due to him all the coins with his distinctive stamp, even the coins he did not issue. Thus, the king had no control over the issue of his coins and, in practice, had legalized counterfeiting. Anybody holding gold could issue financial instruments bearing a promise of the king. Today, in the United States, an equivalent would be for the US Bureau of Engraving and Printing to freely print Federal Reserve notes for anybody who comes with paper that meets the Bureau's specifications. This is a recipe for inflation. Thus, while the supply of monetary instruments should be elastic enough to respond to the demand for them, the issuer should control the methods of creating its monetary instruments. Banks should perform proper underwriting; governments should have budgetary procedures and control over the means used to make physical monetary instruments.

\footnotetext{
${ }^{18}$ More formally, the equilibrium fiscal position is the one that allows the domestic private sector to reach its desired net accumulation of government financial assets: $\Delta\left(F A_{G}-F L_{G}\right)^{*}=-\Delta\left(F A_{D P}-F L_{D P}\right)_{d}=-\Delta\left(F A_{D P}-F L_{D P}\right)$. Framed in terms of national income accounts, the equilibrium fiscal deficit is the one that allows the domestic private sector to achieve its desired net saving $(G-T)^{*}=(S-I)_{d}=(S-I)$. If that condition is not satisfied, aggregate income will change and so will $G$ and $T$, and so will $S$.
} 


\section{Monetization and Demonetization}

The preceding subsections help to understand when something becomes a monetary instrument and when it ceases to be one. A commodity is not a monetary instrument. A commodity can become a monetary instrument but there are several traps to avoid. First, checking for the existence of a medium of exchange is a poor way of determining if the payment is monetary or in-kind. Second, even if this goes in the right direction, checking if a commodity has a constant price (Grierson 1977) is only a preliminary indication of the monetary nature of a commodity. This criterion only indicates that the price of a commodity is administered, but it fails to consider other crucial aspects, such as the existence of a term to maturity. Innes provides a clue to the logic needed to determine if a commodity is a monetary instrument:

A moment's reflection shows that a staple commodity could not be used as money, because ex hypothesi, the medium is equally receivable by all members of the community. Thus if the fishers paid for their supplies in cod, the trader would equally have to pay for their cod in cod, an obvious absurdity. (Innes 1913, p. 378)

If a commodity is used by someone to make payments, and if this initial person accepts back the commodity in payments to him at a defined maturity date, then, given the existence of a clear value in terms of a unit of account and the presence of a sign of the issuer, it is a financial instrument. In addition, if the financial instrument made of the commodity is negotiable, and is accepted back whenever presented to the issuer, it is a monetary instrument. As such, its fair value would be the face value and would be higher than its intrinsic value (otherwise it would stop circulating). Thus, a monetary system based on a gold standard never had gold pieces at the top of the pyramid but it had gold coins. A gold bullion would be a financial instrument if it fulfilled all the conditions for becoming so: negotiable (it is), distinctive sign of the issuer (none), well-defined face value (none, unless the bullion producers say at what price he will accept bullion as payment), and a defined term to maturity (none). A settlement of debts with gold bullion is not a monetary payment but an in-kind payment. The closest monetary instruments to gold bullions are full-bodied coins.

A monetary instrument is demonetized when it ceases to be a promise. This can be done at the initiative of the issuer (e.g., refusal to accept as payment) or, illegally, at the initiative of the bearers (e.g., melting of gold coins, burning paper currency). One should not confuse demonetization and non-monetary use of monetary instruments. For example, collectors may be 
ready to pay a hundred times the face value of a commemorative coin or "special" note; others may collect foreign currencies that nobody will accept in the country of their collectors. In addition, anthropologists note that when coins were introduced in Africa, some indigenous tribes used them both as monetary instruments and as decoration, or even totally forgot about their monetary use. None of these cases represents a demonetization of a financial instrument; they represent a non-monetary use of a monetary instrument. In addition, the monetization is not defined in relation to the fulfillment of a specific function. Bearers may stop using a monetary instrument for its functions - art, superstition, and collectible value may be the reasons they hold it—but it is still a monetary instrument. 


\section{REASONS FOR HOLDING FINANCIAL INSTRUMENTS}

Financial instruments are promises and a promise is a present agreement about a future action. Thus, from the point of view of the issuer, the primary reason to create financial instruments is to implement inter-temporal economic activities of all sorts (productive or speculative). The degree of inter-temporality (term to maturity) depends on the needs of the issuer. In order for these inter-temporal decisions to be financed, the bearer must believe that the inter-temporal decisions of the issuer make sense and are credible. Thus, if one goes more specifically into the reasons for holding financial instruments, one must first look at the expectations that the intertemporal decisions contain. These expectations concern the ability of the issuer to become a creditor. The issuer must have the capacity to entice, or to force, other economic units to become indebted to it so that the issuer can acquire the amount of unit of account they promised to deliver to their creditors.

Government's ability to levy taxes or other obligations seems to have been the preferred method to create an initial willingness to hold its monetary instruments. The population willingly bears these instruments because they could be used to pay the tax debt imposed on all, or part, of the population. When the credibility of this promise was low (for reasons explained above), the provision of collateral through the embedding of precious metal was an additional means to create a willingness to bear government monetary instruments. The financial basis for this artefact disappeared with greater political stability, better enforcement and types of reflux mechanisms, and improvement in the production technology of coins that made forgery very difficult. ${ }^{19}$ This artefact may have persisted for other reasons such as the demonstration of power, culture, or other non-financial purposes.

Financial instruments issued by the private sector allow private issuers to gain immediate access to some financial resources for business or household purposes. The issuer promises to take back his promissory note in the future in addition to providing a reward to the bearers. Households promise to repay their mortgages (i.e., at the maturity date they get their promissory note: the mortgage note), and companies promise to take back their bonds (repay principal due at maturity in exchange for the bond). Households fulfill that promise by earning a

\footnotetext{
${ }^{19}$ While some may argue that a precious metal content is still necessary to provide a hedge against inflation, there is no reason for the government to provide that hedge given that, in today's economy, inflation is usually not caused by government economic activities.
} 
wage, companies do it by selling goods and services; both of them may also fulfill that promise through speculative activities in goods and financial markets (i.e., capital gains). Each of these means of fulfilling a promise creates a demand for the promises of the specific economic unit, and also affects the financial fragility of the economy (Minsky 1986a).

The main problem is that most private issuers have a limited capacity to find people willing to bear their financial instruments. This is the case for two reasons. First, individuals have a limited credit history given their limited lifespan. Their credibility takes time to establish and evaporates once they die. This is less true for well-established businesses that have been around for decades, and can technically operate forever, and issue promises on the routine basis. Second, even if someone has a good credit history, they usually do not have many, or any, debtors; so for most individuals, it is hard to find someone willing to hold their promissory note.

In response to this problem, a new business opportunity emerged: private banking. Banks specialize in evaluating the credibility of promises and are dealers of promissory notes. At the same time, banking involves maturity, credit, and liquidity transformation by swapping promissory notes of different degrees of acceptability. The fact that the credibility of bank promises can be tested quickly and repetitively contributes to their wider acceptance. The main difficulty with banking is that the promises that a bank bears (i.e., its financial assets) are only fulfilled over the long run while the promises that a bank issues (i.e., its financial liabilities) are mostly short-term. Therefore, banks must carefully evaluate the credibility of long-term promises and be rewarded accordingly in order to operate as a going concern. They must also have access to a stable, low-cost refinancing channel (e.g., a central bank). The more successful a bank, the more payments will be directed toward that bank(i.e., the more debtors it will have) and so the more widely its financial instruments will be accepted. This is a tremendous help to non-bank agents in funding their inter-temporal decisions.

To conclude, in the broadest terms, the greater the credibility of the issuer, the greater their ability to find people willing to hold their promises. Indeed, more people will have to make payments to that issuer. This provides the core reason why a specific financial instrument is accepted. Beyond this core reason, economic units may hold a financial instrument to perform transactions now or in the future with people other than the issuer. However, if it ceases to be a financial instrument (e.g., demonetization), these other reasons (store of value, media of exchange, etc.) to hold a financial instrument do not maintain its fair value. 


\section{A ROAD MAP FOR STUDYING MONETARY HISTORY}

One can use the previous framework to study monetary history based on means other than checking if the functions of "money" are present. This leads to a much richer history than just the simple listing of monetary instruments and a brief justification of their monetary nature by acknowledging that they changed hands in payments. This also allows us to make a clear difference between barter and monetary payments.

\section{Cowry Shells}

The case for cowry shells being monetary instruments is often presented by first looking at their history in the Maldives. Relying on the words of an Arab merchant and an Arab historian of the $9^{\text {th }}$ and $10^{\text {th }}$ centuries, Quiggin reports that more than a thousand years ago, cowry shells:

formed the wealth of the royal treasury [...] [and] when funds were getting low, the sovereign sent out servants to cut branches of coconut palm and throw them into the sea. The little mollusks climbed on to the branches and were collected and spread out on the sand to dry until only the empty shells were left. So the royal bank was filled again. Ships from India brought goods to the Maldives and took back millions of shells packed up in thousand in coconut palm leaves. It was a profitable trade, for even in the seventeenth century we hear of 9,000 or 10,000 cowries being bought for a rupee and sold again for three or four times as much on the mainland of India. (Quiggin, 1963, pp. 25-26)

From this description, one cannot conclude that cowries were monetary instruments used by the king to finance the purchase of foreign goods and services. Indeed, it is not explained what the unit of account of the Maldives was and how cowries were monetized. In addition, the role of cowries as monetary instruments is doubtful for the Maldives, even if one uses the functional approach, because cowry shells were worth nothing against goods "except by shipload" (Polanyi 1966, p. 190) - an extremely inconvenient medium of exchange. Maldivian authorities were involved in the trade of cowries with Indian and Arab merchants. They were exporting cowries against imports of other goods - a situation of bilateral trade, not a situation of a cowry monetary system. 
A monetary study of cowry shells would analyze several important points. First, it would explain how the unit of account came into existence: What was the unit of account used? Who imposed it and for what reasons? Second, the analysis would show how the cowry shells were monetized: Who issued them as financial instruments? What were their face and fair nominal values in terms of the unit of account? What was the nature of the promise embedded in the instrument? What were the mechanisms that allowed the cowries to flow back to the issuer? How was the scarcity of the cowry shells managed in order to preserve their purchasing power? Simply recounting that cowry shells were passing hands or were hoarded is not enough.

Fortunately, several authors have conducted more detailed studies, and Forstater (2006) summarizes some of this literature. In the African region of Dahomey, the monarch issued strings of cowries to make payments and had a monopoly on the stringing. Once issued by the government, cowries could be used by residents of Dahomey as medium of exchange. Perhaps, as in New Britain, which used the diwarra (a strip of cowry-like Nassa shells) (Quiggin 1963), each cowry could be detached to make payments in small exchanges. The cowry strings were accepted by the government in payments of taxes. The government controlled the supply of cowries so as to maintain their scarcity by controlling the importation of cowries. The government of Dahomey was able to do it so well that the value of the unit of account was stable from the $17^{\text {th }}$ century to the middle of the $19^{\text {th }}$ century (Polanyi 1966). By controlling the inflows from foreign trade, by taxing and controlling its spending, the government controlled the scarcity of cowries and preserved their purchasing power-the cowry was managed money. When the government of Dahomey failed to do so, "cowrie inflation" prevailed, and ultimately, the cowry monetary system had to be abandoned (Dalton 1965).

\section{Tobacco Leaves in the American Colonies}

The case of Virginia and other U.S. colonies in the $17^{\text {th }}$ and $18^{\text {th }}$ centuries is usually put forward to make the case that the tobacco leaf was a monetary instrument:

Tobacco was an accepted medium of exchange in the southern colonies. Quit rents and fines were payable in tobacco. Individuals missing church were fined a pound of tobacco. In 1618, the governor of Virginia issued an order that directed that "all goods should be sold at an advance of twenty-five percent, and tobacco taken in payment at three shillings per pound, and not more or less, on the penalty of three years of servitude to the Colony." [...] Virginia was using "tobacco notes" as a substitute for currency by 1713 . 
These notes originated after tobacco farmers in Virginia began taking their tobacco crops to warehouses for weighing, testing, and storage [...]. The inspectors at the rolling houses were allowed to issue notes or receipts that represented the amount of tobacco being held in storage for the planter. These notes were renewable and could be used in lieu of tobacco for payment of debts. [...]Fines in Virginia were payable in tobacco. For example, a master caught harboring a slave that he did not own was subject to a fine of 150 pounds of tobacco. The Maryland Tobacco Inspection Act of 1747 was modeled after the Virginia statute. The Maryland statute required tobacco to be inspected and certified before export in order to stop trash from being put in the tobacco. [...] Inspection notes were given for the tobacco that was inspected. Those notes were passed as money in Maryland. The use of warehouse receipts for tobacco and other commodities would spread to Kentucky as settlers began to cultivate that region. (Markham 2002, pp. 4445)

Hence, tobacco leaves served as media of exchange and so, following the narrow functional approach, were monetary instruments. However, what the preceding description actually shows is that the colonies of Virginia and Maryland were at the center of a trading system of tobacco, which was central to the economy of these states (Markham 2002, p. 35). By accepting tax payments (or any other dues) in tobacco at a relatively high fixed price, governments could influence tobacco output, could centralize output collection and redistribution, and could make it easier for farmers - who usually did not have enough monetary instruments because of their scarcity - to pay their taxes. This, however, does not qualify payments in tobacco as monetary payments, but rather as payments in-kind at a price that was administered (Nussbaum 1950, p. 555). Tobacco producers would not have accepted being paid in tobacco for tobacco.

Thus, from the evidence provided, one cannot conclude that tobacco was a monetary instrument. Tobacco was a commodity with an administered price that could be used instead of monetary instruments to settle debts recorded in pounds and to buy goods and services. The previous quote, however, gives us some clues about the monetary system that existed. First, whereas tobacco was not a financial instrument, tobacco notes were a financial instrument of the government warehouses worth a certain number of pounds and collateralized by the value of the weight of tobacco that each note represented. Thus, tobacco notes may have become a monetary instrument if they had a zero term to maturity; nothing clear is said about that. We are only told that they were used "in lieu of tobacco for payment of debts" and "passed as money in 
Maryland." This is a good illustration of how the functional approach may lead to a truncated study of the "money-ness" of a financial instrument, and to focus extensively on an object (tobacco leaf) that does not even possess the qualities necessary to be a financial instrument. Second, the provision of credit through bookkeeping was a common way to avoid the problems of barter:

One method for financing private transactions in the colonies was through records of account kept by tradesmen and planters. Credits and debits were transferred among other merchants and traders. This was a form of "bookkeeping barter" in which goods were exchanged for other goods, and excess credits were carried on account. The barter economy that prevailed in the colonies required "voluminous record-keeping ... to carry over old accounts for many years." This practice would continue through the eighteenth century [...]. (Markham 2002, p. 46)

The bookkeeping system was actually more complicated because credits on an account were sometimes transferable at par (Littleton 1956). Thus, a monetary system based initially on a pound unit was present in the colonies, even though its functioning was not very smooth given the too-high scarcity of top monetary instruments and the localized emergence of bookkeeping transfers. Tobacco leaves were not part of this monetary system. 


\section{CONCLUSION}

The study of monetary history and monetary systems is a complex matter that cannot rely on merely inspecting the functions performed by an object. Anything issued by anybody can be a monetary instrument and any type of material can be used to make a monetary instrument, as these are unimportant determinants of what defines a monetary instrument. The public opinion about what is or is not a monetary instrument also does not matter; popular belief alone cannot turn something into a monetary instrument. ${ }^{20}$ The fact that something is a legal tender, circulates at a fixed price, or is a medium of exchange provides only an initial clue that something is a monetary instrument. What matters is the existence of specific financial characteristics. These characteristics lead to a stable nominal value (parity) in the proper financial environment. This stable nominal value plays a crucial role in the stability of the financial system because it provides a reliable means to pay debts — a reliable means of payment — which promotes liquidity and solvency. However, these characteristics do not guarantee stable purchasing power, and so a monetary instrument may not be a reliable medium of exchange. A significant part of the story of monetary systems has been to try to establish a smoothly working monetary system based on a financial instrument that is both perfectly liquid and has stable purchasing power. This quest has been unsuccessful (only perfect liquidity has been achieved) but it has had a tremendous influence on the view of scholars, politicians and the general population about "money."

This alternative framework has important implications. First, it shows that any modeling must take into account the financial implications of economic decisions. Monetary instruments are specific financial instruments and all financial instruments are contractual bets about the future that involve two parties: a debtor and a creditor. Thus, both sides of the monetary framework must be modeled if we are to have a consistent analysis of monetary affairs. This means that the accounting framework of a model must be stated explicitly (Lavoie and Godley 2007). Second, one can easily understand why Starr (1974) finds a non-zero price for unconvertible unsecured monetary instruments when there are taxes. Because of the nature of monetary instruments, any model that includes them must have individuals with a shortage of monetary instruments (debtors). This is sufficient to create demand for monetary instruments. If the state is not modelled, economic agents indebted to a bank demand bank promises. Third,

\footnotetext{
${ }^{20}$ To use an analogy, one can use a shoe to hammer nails, but it does not make the shoe a hammer. The fact that everybody thinks that shoes are hammers does not turn the shoe into a hammer. If everybody is delusional enough to believe the contrary, there will be many more work-related accidents, and productivity will drop because shoes are not built properly to hammer nails.
} 
related to the previous points, monetary instruments cannot be modeled as pure assets (the " $n$th commodity"), and they are not commodities even if made of a commodity. As the adage goes, "money does not grow on trees." Fourth, a proper analysis of a monetary system involves a detailed analysis of the financial mechanics at play in terms of fair value and purchasing power. A mere description of the object used as medium of exchange and means of payment is a very superficial analysis, and may be misleading. Things other than monetary instruments can be used as a medium of exchange, as well as a means to make final payments. In addition, some monetary instruments may not be perfectly liquid.

Finally, the framework of analysis helps us to understand why using a precious material or having a narrow view of what money is (which led to the Monetarist and gold standard experiments) has a negative impact on the economic system. Given the nature of financial instruments, what matters is the credibility of the issuer. This is determined by economic and political confidence. This brings forward the crucial importance of underwriting in the issuance of financial instruments, as well as the existence of well-defined reflux mechanisms. Issuance must be based on the expectation that the promise can be fulfilled by the issuer. The fulfillment of that promise depends on how reasonable the expectation is-Minsky (1986a) provides great insights here - as well as the mechanisms put in place to make the realization of this expectation possible. As the 2008 financial crisis showed, once again, soundness in underwriting, soundness of the banking structure, and soundness in financial innovations are crucial for a wellfunctioning financial system (Tymoigne and Wray 2014). This requires proactive regulation, supervision and enforcement in the financial industry (some of which can be done internally as the Suffolk Bank experiment shows). In addition, as the Massachusetts experiment shows, reflux mechanisms consistent with the terms of the promise must be in place-as the adage goes, "do not make a promise you cannot keep." All this was poorly understood for a long period of economic history due to the conflation of monetary instruments with commodities ("gold is money"). The focus on the value of the metal content was partly justified when great monetary upheavals occurred, but these monetary disorders partly existed because of the insistence on having a commodity at the foundation of the monetary system. 


\section{REFERENCES}

Boyer-Xambeu, M.T., Deleplace, G. and Gillard, L. (1994) Private Money and Public Currencies. New York: M.E. Sharpe.

Brock, L. (1992) “The Colonial Currency, Prices, and Exchange Rates.” Essays in History, 34: 70-132.

Cecchetti, S.G. (1988) "The Case of the Negative Nominal Interest Rates: New estimates of the term structure of interest rates during the Great Depression." Journal of Political Economy, 96 (6): 1111-1141.

Clouse, J., Henderson, D., Orphanides, A., Small, D. and Tinsley, P. (2000) "Monetary Policy when the Nominal Short-Term Interest Rate is Zero." FEDS paper 2000-51.

Dalton, G. (1965) “Primitive Money.” American Anthropologist 67 (1): 44-65.

Davis, A.M. (1900) Currency and Banking in the Province of Massachusetts Bay, Vol. 1. New York: Macmillan.

Einzig, P. (1966) Primitive Money in Its Ethnological, Historical, and Economic Aspects. $2^{\text {nd }}$ edition. New York, NY: Pergamon Press

Fleming, M.J. and Garbade, K.D. (2004) "Repurchase Agreements with Negative Interest Rates." Federal Reserve Bank of New York Current Issues in Economics and Finance, $10(5): 1-7$.

Forstater, M. (2006) "Tax-Driven Money: Additional Evidence from the History of Thought, Economic History, and Economic Policy." In Setterfield, M. (ed.) Complexity, Endogenous Money and Macroeconomic Theory, 202-220. Cheltenham: Edward Elgar.

Godley W. and Lavoie, M. (2007) Monetary Economics. New York: Palgrave Macmillan.

Goldberg, D. (2005) "Famous Myths of 'Fiat Money'." Journal of Money, Credit and Banking 37 (5): 957-967.

Grierson, P. (1977) The Origins of Money. London: Athlone Press.

Hawtrey, R. (1919) Currency and Credit. New York: Longmans, Green and Co.

Helfferich, K. (1927) Money. New York: Adelphi Co.

Henry, J.F. (2004) "The Social Origins of Money: The Case of Egypt.” In Wray, L.R. (ed.) Credit and State Theories of Money, 79-98. Northampton: Edward Elgar.

Hicks, J.R. (1967) Critical Essays in Monetary Theory. Oxford: Oxford University Press.

Hirschberg, E. (1971) The Nominalistic Principle: A Legal Approach to Inflation, Deflation, Devaluation and Revaluation. Ramat-Gan: Bar-Ilan University. 
Hudson, M. and Wunsch, C. (2004) Creating Economic Order. Bethesda: CDL Press.

Ingham, G. (2000) "Babylonian Madness: On the Historical and Sociological Origins of Money," in Smithin, J. (ed.) What Is Money? New York: Routledge. . (2004) The Nature of Money. Cambridge: Polity Press.

Innes, A.M. (1913) “What is Money?” Banking Law Journal 30(5): 377-408. . (1914) “The Credit Theory of Money.” Banking Law Journal 31(2): 151-168.

Jevons, W.S. (1875) Money and the Mechanism of Exchange. New York, NY: Appleton.

Kemp, A. (1956) The Legal Qualities of Money. New York: Pageant Press.

Keynes, J.M. (1930) A Treatise on Money. London: Macmillan.

Langworthy Taylor, W.G. (1913) The Credit System. New York: Macmillan.

Littleton, A.C. (1956) Studies in the History of Accounting. Homewood: Richard D. Irwin

Mann, F.A. (1992) The Legal Aspect of Money. Oxford: Oxford University Press.

Markham, J.W. (2002) A Financial History of the United States, Vol. 1. New York: M.E. Sharpe.

Mélitz, J. (1974) Primitive and Modern Money: An Interdisciplinary Approach. Reading: Addison-Wesley.

Menger, K. (1892) “On the Origin of Money.” Economic Journal 2 (6): 239-255.

Murad, A. The Paradox of a Metal Standard. Washington, D.C.: Graphic Arts Press. . (1943) “The Nature of Money.” Southern Economic Journal 9 (3): 217-233. . (1954) Private Credit and Public Debt. Washington, DC: Public Affairs Press.

MacLeod, H.D. (1889) The Theory of Credit. London: Longmans and Green. . (1894) Bimetalism. New York: Longmans and Green.

Minsky, H.P. (1986a) Stabilizing an Unstable Economy. New Haven, CT: Yale University Press . (1986b) "Global Consequences of Financial Deregulation." Marcus Wallenberg Papers on International Finance 2 (1): 1-19.

Nissen, H.J., Damerow, P. and Englund, R.K. (1993) Archaic Bookkeeping. Chicago: Chicago University Press. 
Nussbaum, A. (1950) Money and the Law: National and International. Brooklyn: Foundation Press. . (1957) A History of the Dollar. New York: Columbia University Press.

Olivecrona, K. (1957) The Problem of the Monetary Unit. New York: Macmillan.

Polanyi, K. (1957) “The Semantics of Money-Uses.” Reprinted in Dalton, G. (ed.) Primitive, Archaic and Modern Economies, 175-203. Boston: Beacon Press. 1968 . (1966) Dahomey and the Slave Trade. Seattle: University of Washington Press.

Pryor, F.L. (1977) “The Origins of Money.” Journal of Money, Credit and Banking 9 (3): 391409.

Quiggin, A.H. (1949) A Survey of Primitive Money. London: Methuen \& Co. . (1963) The Story of Money. New York: Roy Publisher.

Ritter, L.S. (1963) “An Exposition of the Structure of the Flow-Of-Funds Accounts.” Journal of Finance 18 (2): 219-230.

Schmandt-Besserat, D. (1992) Before Writing, Vol. 1. Austin, TX: University of Texas Press.

Smith, B.D. (1985) "American Colonial Monetary Regimes: The Failure of the Quantity Theory and Some Evidence in Favour of an Alternate View." Canadian Journal of Economics, 18 (3): 531-565

Smith, T. (1811) An Essay on the Theory of Money and Exchange. London: Richardson. . (1832) An Essay on Currency and Banking. Philadelphia: Jasper Hardin.

Starr, R.M. (1974) "The Price of Money in a Pure Exchange Monetary Economy with Taxation." Econometrica 42 (1): 45-54.

Tymoigne, E. and Wray, L.R. (2014) The Rise and Fall of Money Manager Capitalism. New York: Routledge.

Van De Mieroop, M. (2005) "The Invention of Interest." In Goetzmann, W.N. and Rouwenhorst, K.G. (eds.) The Origins of Value: The Financial Innovations that Created Modern Capital Markets, 17-30. Oxford: Oxford University Press.

Vickers, D. (1959) Studies in the Theory of Money: 1690-1776. Philadelphia: Chilton Co.

Walker, F.A. (1878) Money. New York: Henry Holt and Co.

Wray, L.R. (1998) Understanding Modern Money. Northampton: Edward Elgar. . (2012) Modern Money Primer. New York: Palgrave Macmillan. 